\title{
Flipped Classroom Learning Design in Mathematics Learning on Vector Material
}

\author{
Muhammad Wildan Hikmatul Fajar ${ }^{1, \text { a) }}$, Lukman El Hakim², b) \\ ${ }^{12}$ Universiats Negeri Jakarta \\ Email penulis: ${ }^{\text {a) }}$ muhammadwildanhf@gmail.com, ${ }^{\text {b) }}$ lukman_hakim@unj.ac.id
}

\begin{abstract}
The development of learning by involving technology is one of the impacts of the rapid development of technology. Currently educators are still determining the appropriate learning model for the teaching process, the lack of teaching time in schools is one of the problems that arise and understanding student concepts is also the reason student learning outcomes are not satisfactory. There are many challenges faced by teachers and students in learning mathematics today. Several alternative solutions to these challenges can be found in the literature, one of which is by implementing a flipped classroom. In the flipped classroom, learning activities that are usually carried out in the classroom are carried out outside the classroom. Thus, activities in the classroom can be focused on activities that can stimulate students to think at a higher level. Although it looks promising, this kind of learning does not always have a positive impact on student learning. Therefore, this flipped classroom needs to be designed in such a way that it has more value in terms of learning design. Providing flipped classroom learning design elements into this learning will have the potential to increase the quality of mathematics learning. Therefore, this article will review the literature related to the flipped classroom learning design in learning mathematics on vector material. Specifically, this article will examine the definition and design of the flipped classroom, along with the challenges of its implementation. Finally, this article will review studies that have designed and implemented flipped classrooms in mathematics learning, especially in vector material. From the results of the theoretical study, it can be concluded that the steps in the design of vector material flipped classrooms can support mathematics learning and have the opportunity to be developed in various units of education level.
\end{abstract}

Keywords: Learning Design, Flipped Classroom, Mathematics Learning.

\begin{abstract}
Abstrak
Pengembangan pembelajaran dengan melibatkan teknologi menjadi salah satu dampak pesatnya perkembangan teknologi. Saat ini pendidik masih menentukan model pembelajaran yang tepat untuk proses pengajaran, minimnya waktu pengajaran di sekolah menjadi salah satu permasalahan yang muncul dan pemahaman konsep siswa juga menjadi alasan hasil belajar siswa belum memuaskan. Banyak tantangan yang dihadapi oleh guru maupun siswa dalam pembelajaran matematika saat ini. Beberapa alternatif penyelesaian terhadap tantangantantangan tersebut dapat ditemukan di dalam literatur, salah satunya adalah dengan menerapkan flipped classroom. Dalam flipped classroom, kegiatan pembelajaran yang biasanya dilakukan di dalam kelas dilaksanakan di luar kelas. Dengan demikian, kegiatan di dalam kelas dapat difokuskan kepada aktivitas-aktivitas yang bisa menstimulus siswa untuk berpikir pada tingkatan yang lebih tinggi. Meskipun tampak menjanjikan, pembelajaran seperti ini tidak selalu berdampak positif terhadap pembelajaran siswa. Oleh karena itu, flipped classroom ini perlu dirancang sedemikian rupa sehingga memiliki nilai lebih dari segi desain pembelajarannya. Pemberian elemen-elemen desain pembelajaran flipped classroom ke dalam pembelajaran ini akan berpotensi menambah kualitas pembelajaran matematika. Oleh karena itu, artikel ini akan mengkaji pustaka terkait desain pembelajaran flipped classroom dalam pembelajaran matematika pada materi vektor. Secara spesifik, artikel ini akan melakukan kajian terhadap definisi dan desain flipped classroom, beserta dengan tantangan-tantangan implementasinya. Terakhir, artikel ini akan meninjau penelitian-penelitian yang telah mendesain dan menerapkan flipped classroom dalam pembelajaran matematika terutama dalam materi vektor. Dari hasil kajian teoritis, dapat disimpulkan bahwa langkah-langkah dalam desain pembelajaran flipped classroom materi vektor dapat mendukung pembelajaran matematika dan berpeluang untuk dikembangkan dalam berbagai satuan tingkat pendidikan.
\end{abstract}

Kata kunci: Desain Pembelajaran, Flipped Classroom, Pembelajaran Matematika

Copyright (c) 2020 Fajar, Hakim

$\triangle$ Corresponding author:

Email Address: muhammadwildanhf@gmail.com

Received 3 Februari 2020, Accepted 10 Februari 2020, Published 20 Februari 2020

https://doi.org/10.21009/jrpmj.v2i1.12125 


\section{PENDAHULUAN}

Di abad 21 ini guru dituntut untuk dapat mempersiapkan siswa dimasa kemajuan teknologi informasi dan komunikasi (TIK) yang tidak dapat dihindari lagi. Ketika bicara mengenai pendidikan, fokus utama dari perkembangan teknologi ini tentunya langsung tertuju kepada siswa dan guru serta pelaksanaan pembelajaran yang terdapat didalamnya. Maka dari itu, diera teknologi yang luar biasa ini, para pakar keilmuan mencoba mengatasi problematika siswa dalam menerima materi yang diajarkan. Menurut (Ghavifekr et al., 2014) kemampuan informasi, komunikasi dan teknologi (ICT) dapat memberikan pengajaran yang dinamis dan proaktif dalam lingkungan belajar. Sejalan dengan (Johnston, 2017) yang menyatakan bahwa kemajuan dalam alat teknologi seperti video interaktif, kegiatan interaktif di dalam kelas, dan sistem konferensi video membuka jalan dalam mengembangkan pembelajaran secara luas. Penggunaan teknologi dalam pendidikan juga dapat membangun hubungan profesional melalui kolaborasi, pembinaan, dan pendampingan untuk interaksi sosial dalam berbagi ide. Dengan menggunakan berbagai perangkat teknologi, siswa dapat belajar dilokasi dan waktu yang berbeda melalui pembelajaran jarak jauh secara kolaboratif (Zainuddin, Z., 2016). Oleh karena itu, dengan adanya sinergitas antara teknologi dan pembelajaran, diharapkan pelaksanaannya dapat berjalan secara efektif dan efisien.

Beragam latar dan sasaran kegiatan pembelajaran menjadi salah satu alasan mengapa diperlukan desain/rancangan yang khas atau spesifik. Menurut (Bintari Kartika Sari, 2017) secara sederhana desain pembelajaran adalah suatu rancangan yang sistematis dan sistemik untuk mencapai tujuan pembelajaran tertentu. Dalam hal tersebut perlu adanya inovasi dalam pembelajaran demi tercapainya tujuan pembelajaran pula. Salah satu model pembelajaran yang akhir-akhir ini mulai berkembang dan banyak diterapkan dalam pembelajaran adalah flipped classroom. Menurut (Kadry \& Hami, 2014) jika diartikan perkata, flipped classroom dapat berarti kelas yang dibalik. Dalam pelaksanaannya, pembelajaran ini mengkombinasikan pembelajaran di dalam kelas dan di luar kelas sekaligus, dengan bantuan penerapan teknologi. Pendekatan flipped classroom atau kelas terbalik telah mendapatkan perhatian luas selama dekade terakhir dan didasarkan pada gagasan untuk meningkatkan pembelajaran siswa dengan studi mandiri yang disiapkan melalui sumber daya berbasis teknologi diikuti dengan aktivitas belajar mengajar di kelas yang berkualitas tinggi (Lundin et al., 2018).

Flipped classroom merupakan pendekatan pengajaran dan pembelajaran yang berfokus pada keterlibatan siswa (McCallum et al., 2015). Sedangkan menurut (Bergmann \& Sams, 2012) dalam (Cabi, 2020) mengemukakan bahwa model flipped classroom adalah model pedagogis baru di mana guru berbagi sumber daya digital yang telah ditentukan dengan siswa melalui platform di luar kelas, dan konten terkait juga diajarkan melalui platform ini secara asinkron. Maka dari itu, waktu di dalam kelas akan menawarkan lebih banyak kesempatan bagi pengajar untuk melibatkan siswa dan mendorong siswa untuk membangun hubungan dengan teman sebaya dan guru. 
Dalam pembelajaran di sekolah, terkadang siswa sedikit banyak menyukai seluruh mata pelajaran yang diampunya, terutama mata pelajaran matematika. Pandangan siswa yang menilai bahwa matematika itu sulit harus bisa dirubah oleh guru. Matematika merupakan salah satu bidang studi hidup yang perlu dipelajari karena hakikat dari matematika adalah pemahaman terhadap pola perubahan yang terjadi di dalam dunia nyata dan di dalam pikiran manusia serta keterkaitan diantara pola-pola tersebut.

Matematika pada dasarnya merupakan ilmu yang banyak diterapkan dalam bidang ilmu lain, baik itu pada cakupan konten materi bilangan, aljabar, geometri, data dan peluang. Salah satu materi yang sulit dipahami dalam pelajaran matematika yaitu materi vektor. Peserta didik mengalami kesulitan untuk menyelesaikan soal vektor dengan benar, sehingga mengakibatkan nilai peserta didik tidak memuaskan. Kesalahan dalam mengerjakan soal vektor matematika diakibatkan oleh peserta didik yang kurang paham pada materi vektor, sehingga dibutuhkan berbagai cara untuk membelajarkan matematika kepada siswa, yang tentunya sesuai dengan kebutuhan siswa serta tuntutan perkembangan informasi dan teknologi. Dalam hal ini, penulis akan mengkaji secara teoritis bagaimana desain pembelajaran flipped classroom dalam pembelajaran matematika pada materi vektor.

\section{METODE}

Metode penelitian yang digunakan pada penelitian ini adalah literartur review. Kegiatan pembelajaran dengan menerapkan flipped classroom pada dasarnya sama dengan penerapan-penerapan yang lainnya, yakni setelah kegiatan belajar mengajar siswa dapat menghayati dan mengamalkan materi Vektor sebagai bentuk penghayatan dan pengamalan ajaran agama yang dianutnya. Siswa menguasai materi Vektor dengan menunjukkan perilaku jujur, disiplin, tanggung jawab, peduli (gotong royong, kerja sama, toleran, damai), santun, responsif, dan pro-aktif sebagai bagian dari solusi atas berbagai permasalahan dalam berinteraksi secara efektif dengan lingkungan sosial dan alam serta menempatkan diri sebagai cerminan bangsa dalam pergaulan dunia. Siswa memahami, menerapkan, menganalisis pengetahuan faktual, konseptual, prosedural berdasarkan rasa ingin tahunya tentang ilmu pengetahuan, teknologi, seni, budaya, dan humaniora dengan wawasan kemanusiaan, kebangsaan, kenegaraan, dan peradaban terkait penyebab fenomena dan kejadian, serta menerapkan pengetahuan prosedural pada bidang kajian materi Vektor yang spesifik sesuai dengan bakat dan minatnya untuk memecahkan masalah. Siswa mengolah, menalar, dan menyaji dalam ranah konkret dan ranah abstrak terkait dengan pengembangan dari materi Vektor yang dipelajarinya di sekolah secara mandiri, dan mampu menggunakan metoda sesuai kaidah keilmuan

\section{Materi pembelajaran}

Materi pokok yang digunakan dalam kegiatan pembelajarannya adalah Skalar dan vektor serta operasi aljabar vektor.

\section{Metode pembelajaran}


Metode yang digunakan yaitu Scientific Learning dan menggunakan model flipped classroom atau kelas terbalik dengan diawali pembekalan materi yang harus dipelajari siswa di luar jam belajar sekolah atau dilaksanakan di rumah, kemudian di hari berikutnya dilaksanakan dalam satu ruangan guna membahas kebingungan yang dialami oleh siswa ketika melaksanakan kegiatan pembelajaran sebelumnya.

\section{Media pembelajaran}

Dengan menggunakan penerapan model flipped classroom media yang digunakan yakni berupa lembar kerja siswa, laptop atau smartphone, dan media cetak seperti buku, modul, dan gambar.

\section{Sumber belajar}

Sumber belajar yang diperlukan oleh siswa yakni buku penunjang, pengalaman peserta didik, dan perlunya internet juga. Pelaksanaan yang dilakukan di luar jam sekolah tentunya perlu ada koneksi internet untuk penghubung kedalam jejaring media sosial dan untuk dapat melihat materi yang disajikan di dalam internet seperti di Youtube.

\section{Prosedur penelitian:}

\section{Fase pra-kelas}

Pada fase pra-kelas ini digunakan untuk melibatkan siswa dalam memahami materi yang diberikan melalui platform media. Bahan bacaan yang relevan digunakan berupa online atau hardcopy atau dalam bentuk video pembelajaran yang berkaitan dengan topik mata pelajaran matematika diberikan kepada siswa sebagai pekerjaan rumah. Pekerjaan rumah tersebut menjadi keadaan penting untuk siswa dalam memahami materi yang selanjutnya digunakan untuk diskusi ketika nanti di dalam kelas terkait materi tersebut.

\section{Fase di dalam kelas}

Fase ini digunakan untuk kegiatan pembelajaran yang berpusat pada siswa. Pada saat di kelas, siswa berperan dalam kegiatan yang aktif, seperti problem solving (individu atau grup), diskusi atau kegiatan kelompok. Selama kegiatan pembelajaran, sesi tanya jawab dilakukan berdasarkan tugas pekerjaan rumah, sesi ini difasilitasi oleh pendidik. Namun, kadang-kadang kegiatan di dalam kelas dapat berupa sesi pemecahan masalah berdasarkan topik mata pelajaran matematika yang dipelajari.

\section{Fase pasca-di luar kelas}

Pada fase ini siswa melakukan penguatan pemahaman. Dengan kegiatan yang dilakukannya adalah mempelajari dan merekap pertanyaan dan masalah yang dibahas pada saat di dalam kelas.Meskipun video dan platform online adalah alat penting dalam praktik flipped classroom dalam 
pembelajaran matematika, guru tidak boleh mengabaikan faktor signifikan lainnya yang mempengaruhi keberhasilan belajar siswa seperti interaksi, motivasi, dan keterlibatan siswa. Ini mungkin juga terlihat lebih khusus pada berbagai strategi dan desain pedagogis seperti desain pembelajaran flipped classroom dalam pembelajaran matematika yang khusus dan jenis pelajar atau gaya belajarnya. Penulis percaya bahwa strategi pengajaran guru seperti dalam desain pembelajaran flipped classroom dalam pembelajaran matematika selalu terintegrasi dan sinkron dengan gaya belajar siswa. Oleh karena itu, pengajar dapat mengembangkan berbagai strategi dalam membalik kelas dengan menyesuaikan dengan gaya belajar siswa tanpa mengabaikan materi atau silabus.

\section{HASIL DAN PEMBAHASAN}

Hasil penelitian menunukkan desain pembelajaran flipped classroom dalam pembelajaran matematika yaitu

\section{Kegiatan pendahuluan}

Pada tahap orientasi, guru melakukan pembukaan dengan salam pembuka, memanjatkan syukur kepada Tuhan YME dan berdoa untuk memulai pembelajaran. Guru memeriksa kehadiran peserta didik sebagai sikap disiplin. Guru menyiapkan fisik dan psikis peserta didik dalam mengawali kegiatan pembelajaran. Pada tahap apersepsi, Guru mengaitkan materi/tema/kegiatan pembelajaran yang akan dilakukan dengan pengalaman peserta didik dengan materi/tema/kegiatan sebelumnya. Guru mengingatkan kembali materi prasyarat dengan bertanya. Guru mengajukan pertanyaan yang ada keterkaitannya dengan pelajaran yang akan dilakukan. Guru selanjutnya memberikan gambaran tentang manfaat mempelajari pelajaran yang akan dipelajari dalam kehidupan sehari-hari. Jika materitema/projek ini kerjakan dengan baik dan sungguh-sungguh ini dikuasai dengan baik, maka peserta didik diharapkan dapat menjelaskan tentang materi. Sifat-sifat dan operasi aljabar vector, dan pengertian vector sebagai besaran yang memiliki besar dan arah secara geometri. Guru menyampaikan tujuan pembelajaran pada pertemuan yang berlangsung. Guru mengajukan pertanyaan.

Pada tahap pemberian acuan. Guru memberitahukan materi pelajaran yang akan dibahas pada pertemuan saat itu. Guru memberitahukan tentang kompetensi inti, kompetensi dasar, indikator, dan KKM pada pertemuan yang berlangsun. Tahap selanjutnya adalah tahap pembagian kelompok belajar. Pada tahap ini, guru menjelaskan mekanisme pelaksanaan pengalaman belajar sesuai dengan langkahlangkah pembelajaran.

\section{Kegiatan inti}


Kegiatan Literasi (Stimulus) dalam kegiatan inti antara lain peserta didik diberi motivasi atau rangsangan untuk memusatkan perhatian pada topik materi sifat-sifat dan operasi aljabar vector, dan pengertian vector sebagai besaran yang memiliki besar dan arah secara geometris dengan berbagai cara. Pada cara mendengar, pemberian penjelasan secara singkat tentang materi sifat-sifat dan operasi aljabar vector, dan pengertian vector sebagai besaran yang memiliki besar dan arah secara geometris oleh guru. Pada aktivitas menyimak, penjelasan pengantar kegiatan secara garis besar/global tentang materi pelajaran mengenai materi.

Pada tahap kreativitas, guru menyimpulkan tentang point-point penting yang muncul dalam kegiatan pembelajaran yang dilakukan di luar jam sekolah atau di rumah berupa laporan hasil pengamatan secara tertulis tentang materi sifat-sifat dan operasi aljabar vector, dan pengertian vector sebagai besaran yang memiliki besar dan arah secara geometris. Siswa menjawab pertanyaan tentang materi sifat-sifat dan operasi aljabar vector, dan pengertian vector sebagai besaran yang memiliki besar dan arah secara geometris yang terdapat pada buku pegangan peserta didik atau lembar kerja yang telah disediakan. Siswa bertanya tentang hal yang belum dipahami, atau guru melemparkan beberapa pertanyaan kepada siswa berkaitan dengan materi sifat-sifat dan operasi aljabar vector, dan pengertian vector sebagai besaran yang memiliki besar dan arah secara geometris yang akan selesai dipelajari. Siswa menyelesaikan uji kompetensi untuk materi sifat-sifat dan operasi aljabar vector, dan pengertian vector sebagai besaran yang memiliki besar dan arah secara geometris yang terdapat pada buku pegangan peserta didik atau pada lembar lerja yang telah disediakan secara individu untuk mengecek penguasaan siswa terhadap materi pelajaran.

\section{Kegiatan penutup}

Pada kegiatan penutup ini, siswa membuat resume (Creativity) dengan bimbingan guru tentang point-point penting yang muncul dalam kegiatan pembelajaran tentang materi sifat-sifat dan operasi aljabar vector, dan pengertian vector sebagai besaran yang memiliki besar dan arah secara geometris yang baru dilakukan. Siswa mengagendakan pekerjaan rumah untuk materi pelajaran sifat-sifat dan operasi aljabar vector, dan pengertian vector sebagai besaran yang memiliki besar dan arah secara geometris yang baru diselesaikan. Siswa mengagendakan materi atau tugas projek/produk/portofolio/unjuk kerja yang harus mempelajarai pada pertemuan berikutnya di luar jam sekolah atau dirumah. Guru memeriksa pekerjaan siswa yang selesai langsung diperiksa untuk materi pelajaran sifat-sifat dan operasi aljabar vector, dan pengertian vector sebagai besaran yang memiliki besar dan arah secara geometris. pserta didik yang selesai mengerjakan tugas projek/produk/portofolio/unjuk kerja dengan benar diberi paraf serta diberi nomor urut peringkat, untuk penilaian tugas. Guru memberikan penghargaan untuk materi pelajaran sifat-sifat dan operasi aljabar vector, dan pengertian vector sebagai besaran yang memiliki besar dan arah secara geometris kepada kelompok yang memiliki kinerja dan kerjasama yang baik. 


\section{KESIMPULAN}

Pendekatan pengajaran dan pembelajaran seperti flipped classroom atau ruang kelas terbalik menawarkan peluang untuk membahas keberhasilan akademis siswa. Telah didefinisikan konsep kegiatan pembelajaran sebagai landasan untuk pengembangan perangkat desain kegiatan pembelajaran yang bertujuan untuk memberikan pedoman yang mudah digunakan bagi praktisi untuk membuat keputusan yang diinformasikan secara pedagogis dalam merancang kegiatan pembelajaran dan membuat pilihan tentang penggunaan alat dan sumber daya untuk mendukungnya.

Berdasarkan karakterisik model pembelajaran flipped classroom yaitu dapat membantu siswa belajar baik di dalam maupun di luar kelas sehingga siswa terlibat langsung dalam proses pembelajaran matematika dan seiring dengan perkembangan informasi dan teknologi yang memang menuntut guru untuk menerapkan teknologi dalam kegiatan pembelajaran. Dengan demikian, secara teoritis dengan mendesain pembelajaran pembelajaran flipped classroom ini dengan baik, mempunyai potensi untuk diterapkan dalam pembelajaran matematika khususnya pada materi vektor.

Tinjauan literatur menunjukkan bahwa ada peningkatan kontribusi terhadap lingkungan pendidikan dengan penggunaan flipped classroom. Pertama, aplikasi siswa tentang topik yang dipelajari dapat disediakan dan juga semua tingkatan Taksonomi Bloom dapat dicapai dengan menggunakan model flipped classroom. Siswa didorong untuk keluar dari kelas untuk belajar secara mandiri dari tempat dan waktu dan juga untuk memilih strategi belajar yang paling berguna untuk pembelajaran mereka sendiri. Selain itu, ditemukan bahwa instruktur yang menggunakan model kelas terbalik meningkatkan jenis sumber daya yang mereka miliki, mengalami diskusi reflektif, dan berbagi praktik instruksional mereka satu sama lain.

Ditemukan bahwa model flipped classroom telah diterapkan dalam berbagai disiplin ilmu pendidikan dengan tujuan meningkatkan interaksi dan waktu kontak yang dipersonalisasi antara siswa dan instruktur di kelas. Mayoritas studi menunjukkan bahwa ada perubahan positif yang signifikan dalam pandangan siswa terhadap pendekatan flipped classroom. Namun, sekali lagi kesimpulan ini masih bersifat teoritis sehingga dibutuhkan penelitian lebih lanjut dengan cara menerapkan dalam pembelajaran matematika yang sesungguhnya untuk menentukan spesifikasi desain flipped classroom pada materi vektor dan untuk secara intensif meneliti penggunaan teknologi dan instrumen penilaian yang unggul agar mendapatkan bukti secara empiris.

\section{DAFTAR PUSTAKA}

Albalawi, A. S. (2018). The effect of using flipped classroom in teaching calculus on students' achievements at university of Tabuk. International Journal of Research in Education and Science, 4(1), 198-207. https://doi.org/10.21890/ijres.383137 
Ayu Puspitawati, O., Kristen Satya Wacana, U., \& Oktazella Ayu Puspitawati, K. (2017). Pengembangan Desain Pembelajaran Tematik Terpadu Berbasis Kebutuhan Belajar Siswa Kelas 3 Sekolah Dasar. Jurnal Penelitian Tindakan Dan Pendidikan, 3(2), 2017.

Bennett, S., Lockyer, L., \& Agostinho, S. (2004). Investigating how learning designs can be used as a framework to incorporate learning objects. Beyond the Comfort Zone: Proceedings of the 21st ASCILITE Conference, 2003, 116-122.

Bintari Kartika Sari. (2017). Desain Pembelajaran Model ADDIE dan Impelentasinya dengan Teknik Jigsaw. Prosiding Seminar Nasional Pendidikan : Tema "Desain Pembelajaran Di Era ASEAN Economic Community (AEC) Untuk Pendidikan Indonesia Berkemajuan ,”94-96, 87-102. http://eprints.umsida.ac.id/432/1/ARTIKEL Bintari Kartika Sari.pdf

Bishop, J. L., \& Verleger, M. A. (2013). The flipped classroom: A survey of the research. ASEE Annual Conference and Exposition, Conference Proceedings. https://doi.org/10.18260/1-2--22585

Bloom, \& S., B. (1969). Taxonomy of educational objectives : The classification of educational goals. Cognitive Domain. https://ci.nii.ac.jp/naid/10025289849

Britain, S. (2004). A review of learning design: Concept, specifications and tools. Retrieved January, 9(May).www.jisc.ac.uk/uploaded_documents/ACF83.doc

Butt, A. (2014). STUDENT VIEWS ON THE USE OF A FLIPPED CLASSROOM APPROACH: EVIDENCE FROM AUSTRALIA. Business Education, 6(1), 33-44.

Cabi, E. (2020). International Review of Research in Open and Distributed Learning The Impact of the Flipped Classroom Model on Students ' The Impact of the Flipped Classroom Model on Students ' Academic Achievement.

Çetinkaya, M. (2017). Designing and Applying Web Assisted Activities to be Used in Flipped Classroom Model. International Journal of Evaluation and Research in Education (IJERE), 6(2), $128-137$.

Conole G, \& K, F. (2005). A learning design toolkit to create pedagogically. Journal of Interactive Media in Education, 08(1).

Crouch, C. H., \& Mazur, E. (2001). Peer Instruction: Ten years of experience and results. American Journal of Physics, 69(9), 970-977. https://doi.org/10.1119/1.1374249

Dewey, J. (1966). DEMOCRACY AND EDUCATION, An Introduction to the Philosophy of Education. 465.

Directions, F., Journal, S., April, N., \& Chun, D. M. (2019). International Forum of Educational Technology \& Society Published by : International Forum of Educational Technology \& Society Linked references are available on JSTOR for this article : Current and Future Directions in TELL. Journal of Educational Technology \& Society, 22(2), 14-25.

Fredriksen, H. (2021). Exploring Realistic Mathematics Education in a Flipped Classroom Context at the Tertiary Level. International Journal of Science and Mathematics Education, 19(2), 377-396. https://doi.org/10.1007/s10763-020-10053-1 
Ghavifekr, S., Razak, A., Ghani, M., Ran, N., Meixi, Y., \& Tengyue, Z. (2014). ICT Integration in Education: Incorporation for Teaching \& Learning Improvement. Malaysian Online Journal of Educational Technology, 2(2), 24-45.

Halili, S. H., \& Zainuddin, Z. (2015). Flipping the Classroom: What we know and what we don't. The Online Journal of Distance Educationa and E-Learning, 3(1), 15-22.

Hamdan, N., McKnight, P., McKnight, K., \& Arfstrom, K. M. (2013). The flipped learning model: A white paper based on the literature review titled a review of flipped learning. Flipped Learning Network, $\mathrm{c}$ $1-15$. http://www.flippedlearning.org/cms/lib07/VA01923112/Centricity/Domain/41/WhitePaper_Flipp edLearning.pdf

Jdaitawi, M. (2019). The effect of flipped classroom strategy on students learning outcomes. International Journal of Instruction, 12(3), 665-680. https://doi.org/10.29333/iji.2019.12340a

Jonathan Bergmann, A. S. (2012). Flip Your Classroom: Reach Every Student in Every Class Every Day. DC: Internal Society for Technology in Education. https://books.google.co.id/books?hl=id\&lr=\&id=-

YOZCgAAQBAJ\&oi=fnd\&pg=PR7\&dq=Flip+your+classroom:+Reach+every+student+in+every +class+every+day.++Washington,+DC:+Internal+Society+for+Technology+in+Education.\&ots= AGdiMPtljj\&sig=axzQy-UeopEkLDPC7iYlA4jTgfw\&re

Kadry, S., \& Hami, A. El. (2014). Flipped Classroom Model in Calculus II. Education, 4(4), 103-107. https://doi.org/10.5923/j.edu.20140404.04

Kay, R., \& Kletskin, I. (2012). Evaluating the use of problem-based video podcasts to teach mathematics in higher education. Computers and Education, 59(2), 619-627. https://doi.org/10.1016/j.compedu.2012.03.007

Kim, M. K., Kim, S. M., Khera, O., \& Getman, J. (2014). The experience of three flipped classrooms in an urban university: An exploration of design principles. Internet and Higher Education, 22, 3750. https://doi.org/10.1016/j.iheduc.2014.04.003

Kong, S. C. (2014). Developing information literacy and critical thinking skills through domain knowledge learning in digital classrooms: An experience of practicing flipped classroom strategy. Computers and Education, 78, 160-173. https://doi.org/10.1016/j.compedu.2014.05.009

Krathwohl, D. R., \& Anderson, L. W. (2010). Merlin C. Wittrock and the revision of bloom's taxonomy. Educational Psychologist, 45(1), 64-65. https://doi.org/10.1080/00461520903433562

Larsen, J. (2015). Adult Students' Experiences of a. Flipped Mathematics Classroom. Adults Learning Mathematics: An International Journal, 10(1), 50-67.

Love, B., Hodge, A., Grandgenett, N., \& Swift, A. W. (2014). Student learning and perceptions in a flipped linear algebra course. International Journal of Mathematical Education in Science and Technology, 45(3), 317-324. https://doi.org/10.1080/0020739X.2013.822582 
Lundin, M., Bergviken Rensfeldt, A., Hillman, T., Lantz-Andersson, A., \& Peterson, L. (2018). Higher education dominance and siloed knowledge: a systematic review of flipped classroom research. International Journal of Educational Technology in Higher Education, 15(1). https://doi.org/10.1186/s41239-018-0101-6

Mason, G. S., Shuman, T. R., \& Cook, K. E. (2013). Comparing the effectiveness of an inverted classroom to a traditional classroom in an upper-division engineering course. IEEE Transactions on Education, 56(4), 430-435. https://doi.org/10.1109/TE.2013.2249066

McCallum, S., Schultz, J., Sellke, K., \& Spartz, J. (2015). An Examination of the Flipped Classroom Approach on College Student Academic Involvement. International Journal of Teaching and Learning in Higher Education, 27(1), 42-55. http://www.isetl.org/ijtlhe/

Muir, T., \& Geiger, V. (2016). The affordances of using a flipped classroom approach in the teaching of mathematics: a case study of a grade 10 mathematics class. Mathematics Education Research Journal, 28(1), 149-171.

https://doi.org/10.1007/s13394-015-0165-8

Pramita, M., Mulyati, S., \& Susanto, H. (2016). Implementasi Desain Pembelajaran pada Kurikulum 2013 dengan Pendekatan Kontekstual. Jurnal Pendidikan, 1(3), 289-296.

Ramaglia, H. (2016). The flipped mathematics classroom: A mixed methods study examining achievement, active learning, and perception. Dissertation Abstracts International Section A: Humanities and Social $\quad$ Sciences, http://ovidsp.ovid.com/ovidweb.cgi?T=JS\&PAGE=reference \&D=psyc13\&NEWS=N\&AN=201642145-164

Ramakrishnan, \& JohnsiPriya. (2016). Effectiveness of Flipped Classroom in Mathematics Teaching. International Journal of Research -GRANTHAALAYAH, 4(10(SE)), 57-62. https://doi.org/10.29121/granthaalayah.v4.i10(se).2016.2469

Schallert, S., Lavicza, Z., \& Vandervieren, E. (2020). Merging flipped classroom approaches with the 5E inquiry model: a design heuristic. International Journal of Mathematical Education in Science and Technology, 0(0), 1-18. https://doi.org/10.1080/0020739X.2020.1831092

Smallhorn, M. (2017). The flipped classroom: A learning model to increase student engagement not academic achievement. Student Success, 8(2), 43-53. https://doi.org/10.5204/ssj.v8i2.381

Smith, A., \& Westendorf, E. (n.d.). The Flipped Classroom.

Staker, B. H., \& Horn, M. B. (2012). Classifying K - 12 Blended Learning. May.

Stone, B. B. (2012). Flip Your Classroom to Increase Active Learning and Student Engagement. 28th Annual Conference on Distance Teaching \& Learning, 1-5. http://www.uwex.edu/disted/conference/Resource_library/proceedings/56511_2012.pdf

Umam, K., Nusantara, T., Parta, I. N., Hidayanto, E., \& Mulyono, H. (2019). An application of flipped classroom in mathematics teacher education programme. International Journal of Interactive Mobile Technologies, 13(3), 68-80. https://doi.org/10.3991/ijim.v13i03.10207 
Uzunboylu, H., \& Karagozlu, D. (2015). Flipped classroom: A review of recent literature. World Journal on Educational Technology: Current Issues, 7(2), 142-147. https://doi.org/10.18844/wjet.v7i2.46

Vaughan, M. (2014). Flipping the Learning: An Investigation into the Use of the Flipped Classroom Model in an Introductory Teaching Course. Education Research and Perspectives, 41(1), 25-41.

Wasserman, N. H., Quint, C., Norris, S. A., \& Carr, T. (2017). Exploring Flipped Classroom Instruction in Calculus III. International Journal of Science and Mathematics Education, 15(3), 545-568. https://doi.org/10.1007/s10763-015-9704-8

Yildirim, F. S., \& Kiray, S. A. (2017). Flipped classroom model in education. International Journal of Social Sciences and Education Research, 3(5 S), 1904-1916. https://doi.org/10.24289/ijsser.348068

Zainuddin, Z., \& S. H. H. (2016). (2016). Flipped Classroom Research and Trends from Different Fields of Study." The International Review of Research in Open and Distributed Learning IRRODL,. Journal of Chemical Information and Modeling, 6(2), 1689-1699. http://doi.wiley.com/10.1002/ceas.12013\%0Ahttps://www.researchgate.net/publication/31708733 0\%0Ahttps://repositories.lib.utexas.edu/handle/2152/39127\%0Ahttps://cris.brighton.ac.uk/ws/port alfiles/portal/4755978/Julius+Ojebode\%27s+Thesis.pdf\%0Ausir.salford.a

How to cite : Muhammad, W. H. F., \& Lukman, E. H., 2020. Flipped Classroom Learning Design in Mathematics Learning on Vector Material. Jurnal Riset Pendidikan Matematika Jakarta. 2(1). 1-7. https://doi.org/10.21009/irpmj.v2i1.12125

To link to this article: https://doi.org/10.21009/jrpmj.v2i1.12125 